\title{
Evaluation of Basic and Major Items in the Treating of Wastewater; Experimental Investigation
}

\author{
Abdolrahim Zarei ${ }^{1}$, Farshad Farahbod ${ }^{2,}$ * \\ ${ }^{1}$ Department of Chemical Engineering, Sirjan Branch, Islamic Azad University, Sirjan, Iran \\ ${ }^{2}$ Department of Chemical Engineering, Firoozabad Branch, Islamic Azad University, Firoozabad, Iran
}

Email address:

f.farahbod@iauf.ac.ir (F. Farahbod)

${ }^{*}$ Corresponding author

To cite this article:

Abdolrahim Zarei, Farshad Farahbod. Evaluation of Basic and Major Items in the Treating of Wastewater; Experimental Investigation. Science Journal of Analytical Chemistry. Vol. 5, No. 1, 2017, pp. 12-16. doi: 10.11648/j.sjac.20170501.13

Received: September 20, 2016; Accepted: December 2, 2016; Published: March 1, 2017

\begin{abstract}
The experiments were conducted to measure the important parameters in quality of treatment by addition of four different amounts of nano two metal oxides 1, 1.5,2 and 2.5 gr. The value of zeta potential and oil and grease is investigated. The results show the better performance of nano ferric oxide in coagulation and flocculation by lower amount of zeta potential, ammonia, phenol and sulfide and oil, grease elimination than aluminum oxide. However the value of slug volume index in treated wastewater by nano ferric oxide is higher than that is obtained with nano aluminum oxide. The obtained results show the higher values of zeta potential in about $1 \%, 3 \%, 11 \%$ and $5 \%$ using aluminum oxide than those are obtained using nano ferric oxide show the better coagulation and flocculation in using nano ferric oxide nano coagulant.
\end{abstract}

Keywords: Pretreatment Reactor, Sea Ecosystem, Softening Process, Wastewater Treatment, Desalination, Nano Coagulants

\section{Introduction}

Although desalination units have been grown up, but exit brine stream is usually drained into the sea ecosystem. Moreover, annually a large quantity of concentrated brine is discharged into the sea (Khiari et al., 2010; Gao et al., 2009; Pa et al., 2009; Yana et al., 2009; Wu et al., 2011; Setiawan et al., 2009). By treatment of this saline wastewater, it is possible to eliminate the hazardous effects of salinity on sea ecosystem. Additionally two valuable matters, salt and sweet water can be produced.

Total hardness and turbidity of wastewater must be reduced during pretreatment process of wastewater to produce Sodium Chloride salt (Lee at al., 2010; Yana et al., 2009). Coagulants are the matters used to decrease total hardness of wastewater. The pretreatment process includes 3 steps: coagulation, flocculation and sedimentation. Improving the efficiency of pretreatment process depends on water specifications and also the operating parameters (Wang, Lee et al., 2010; Jangkorn et al., 2011; Al-Jasser, 2011). The optimum mixing rate of first pretreatment reactor, type of coagulant, ratio of sodium carbonate to coagulant and sodium hydroxide to coagulant are some of the important factors in operating conditions. Polyelectrolytes or mixture of coagulants can be used to improve the efficiency of total hardness removal (Nan et al., 2009; Wang, Zhoua at al., 2009).

In this research various binary mixtures of three mineral coagulants were investigated quantitatively and qualitatively. The optimum amounts of Sodium Carbonate to coagulant ratio and Sodium Hydroxide to coagulant ratio were studied for each coagulant individually. This shows that the best ratio for Sodium Carbonate to coagulant is three and for Sodium Hydroxide to coagulant are four.

\section{Materials and Methods}

\subsection{Materials}

Experiments are managed for the brine wastewater of Tehran petroleum refinery which exits from desalination unit. Table 1 introduces specifications of wastewater. Three commercial mineral coagulants, Aluminum oxide, $\mathrm{Al}_{2} \mathrm{O}_{3}$, 
Ferric oxide, $\mathrm{Fe}_{2} \mathrm{O}_{3}$, as nano coagulants are used in the pretreatment process. Moreover in softening process Sodium Carbonate and Sodium Hydroxide must be added to the wastewater. The previous researches in this field are focused on finding the optimum ratio of Sodium Carbonate to coagulant and also Sodium Hydroxide to coagulant and these ratios are used in this work too. These proper values are 3 and 4 , respectively.

Three groups of mixture of couple mineral coagulants which contain different compositions are examined to investigate the best mixture to decrease total hardness.

Table 1. Specifications of concentrated brine wastewater.

\begin{tabular}{lll}
\hline Composition & Unit & Brine outlet line \\
\hline $\mathrm{Ca}++$ & ppm as $\mathrm{CaCO}_{3}$ & 8934.5 \\
$\mathrm{Mg}++$ & $\mathrm{ppm}$ as $\mathrm{CaCO}_{3}$ & 23581 \\
Total hardness & ppm as $\mathrm{CaCO}_{3}$ & 32515.5 \\
Specific Gravity at $15 \mathrm{c}$ & & 1.06 \\
$\mathrm{pH}$ & & 8.6 \\
Viscosity (Kinematic) & $\mathrm{mm}^{2} / \mathrm{s}$ & 0.72 \\
TSS & $\mathrm{g} / 1$ & Trace \\
Total Dissolved Solids & $\mathrm{g} / 1$ & 63.8 \\
\hline
\end{tabular}

\subsection{Experimental Apparatus}

Experiments are held in two pretreatment reactors. The capacity of each reactor is 8 liter and each of them equipped by a mixer. The speed of the mixers can be changed by a "control box".

\section{Results and Discussion}

\subsection{The Basic Items in the Treatment Process by Nano Particles}

Important parameters in pretreatment of wastewater to drain into the environment are investigated in this experimental work. So, different ranges of both nano ferric and aluminum oxide are used to find the proper operation conditions in pretreatment of wastewater.

\subsection{The Effect of Ferric Oxide on the Pretreatment Properties}

The stability of suspension is shown as amount of zeta potential. The higher absolute magnitude of zeta potential shows the more stable colloidal dispersions. The higher zeta potential obtains the higher value of repulsion forces and stable colloidal dispersion. Figure 1 shows the effect of addition of nano ferric oxide on the value of zeta potential. The results show that the addition of nano ferric oxide decreases the value of zeta potential and so leads to the better coagulation and flocculation.

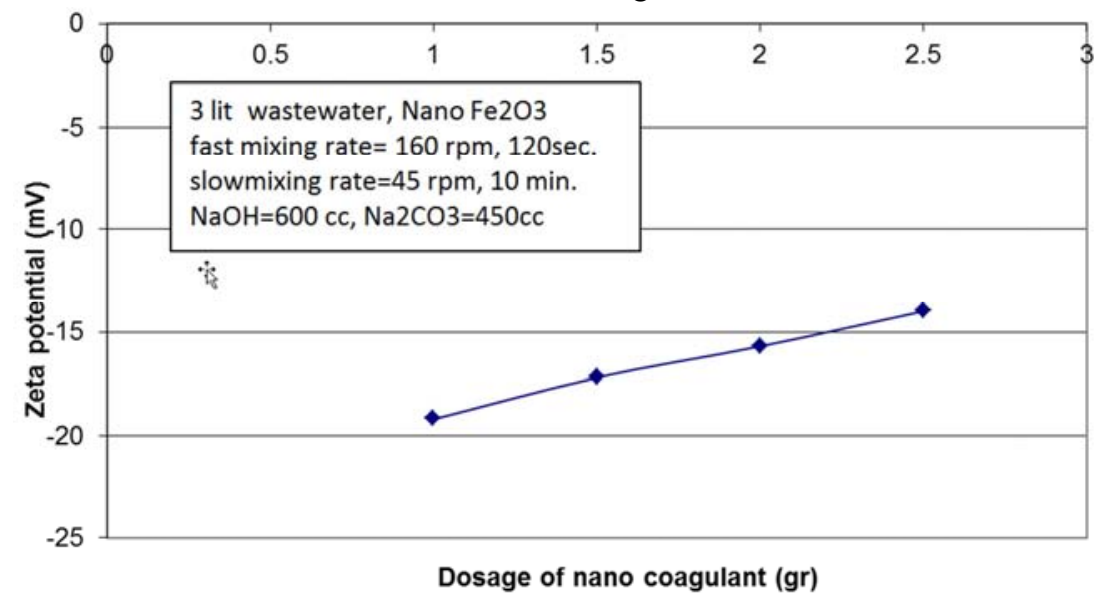

Figure 1. The amount of zeta potential versus nano coagulant.

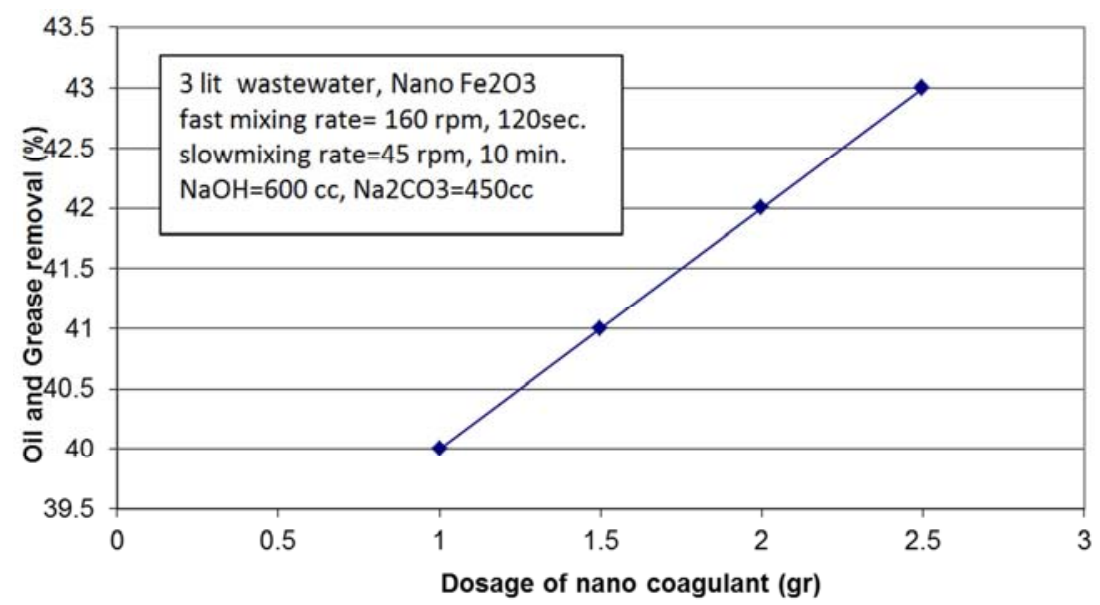

Figure 2. The amount of oil and grease removal versus nano coagulant. 
The addition of nano coagulant is evaluated in oil and grease removal percentage in Figure 2. Results show the positive effect of nano coagulant addition in oil and grease removal. The changes in value of nano coagulant from 1 gr to 2.5 gr increase the amount of oil removal percentage from $40 \%$ to $43 \%$. This shows the $3 \%$ increase in the amount of oil removal percentage. Oil and grease may bond with the coagulant structure or may trap in the flocs.

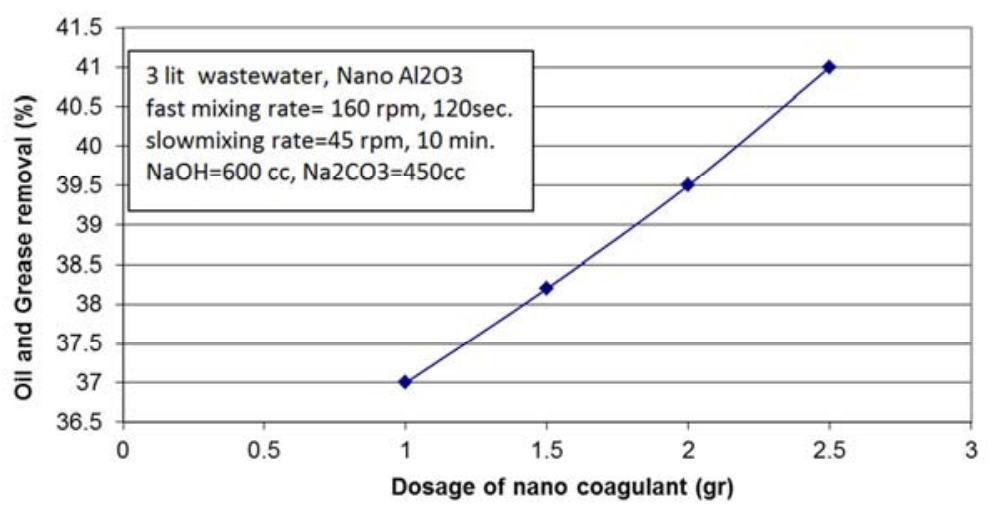

Figure 3. Oil and grease removal versus aluminum oxide nano coagulant.

The amount of oil and grease elimination by aluminum oxide usage is shown in Figure 3. The removal percentage of oil and grease increases from $37 \%$ to $41 \%$ by addition of $1 \mathrm{gr}$ to $2.5 \mathrm{gr}$ of nano aluminum oxide as coagulant. With equal amount of nano coagulant the performance of nano ferric oxide shows the better results about $8 \%, 7 \%, 6 \%$ and $4 \%$ than those are shown using nano aluminum oxide.

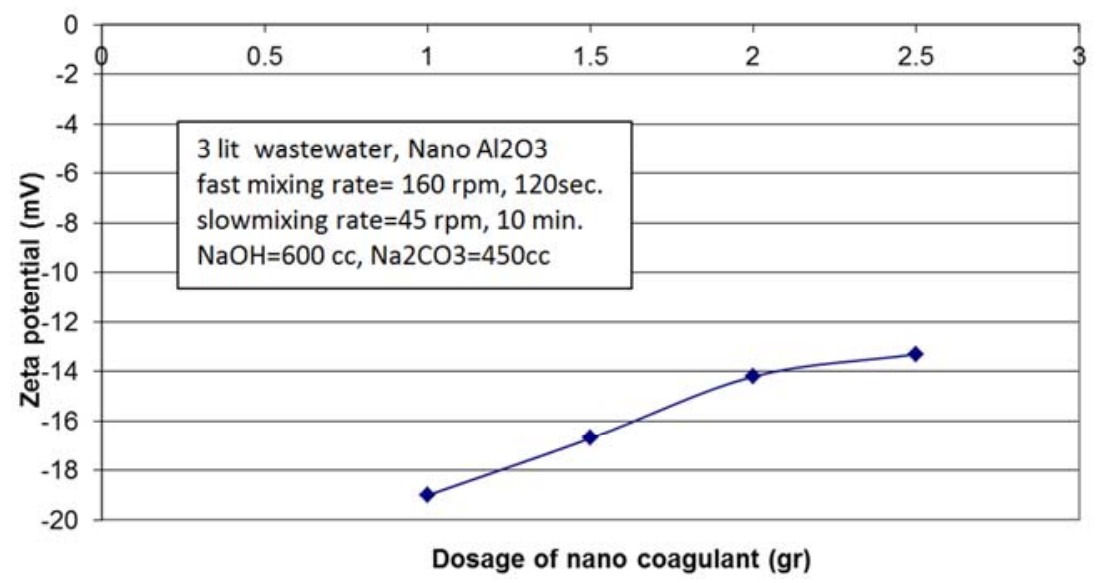

Figure 4. Zeta potential versus aluminum oxide nano coagulant.

Figure 4 shows the value of zeta potential as the factor of stability of colloidal suspension. The higher values of zeta potential in about $1 \%, 3 \%, 11 \%$ and $5 \%$ using aluminum oxide than those are obtained using nano ferric oxide show the better coagulation and flocculation in using nano ferric oxide nano coagulant. This may depends on the nature of ferric oxide than aluminum oxide in bonding with the contaminants.

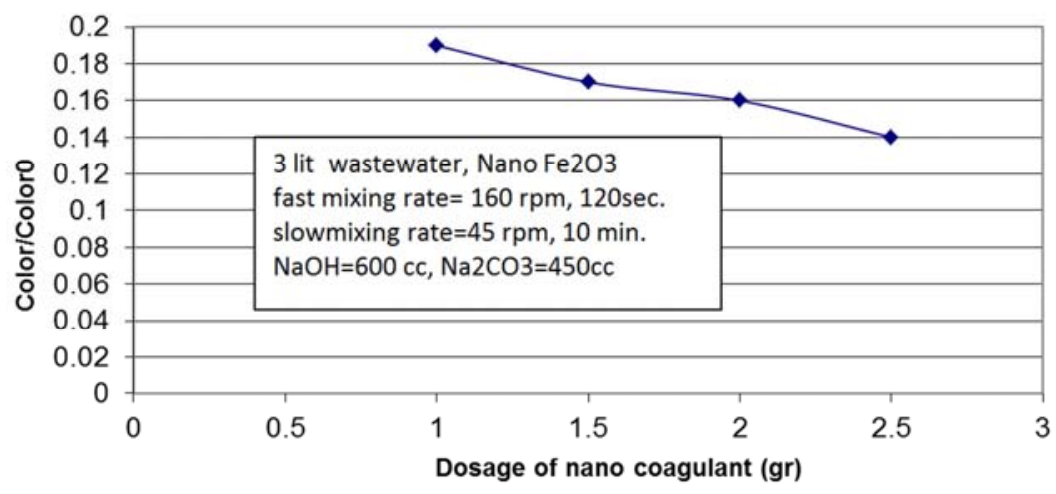

Figure 5. The effect of amount of nano ferric oxide on value of color/color0. 
Figure 5 shows the effect of usage of nano ferric oxide on the fraction of color/color0. This is one factor to show the quality of clearance of wastewater. The increase in the coagulant dosage decreases this value. This shows the power of coagulant in elimination of component which makes turbidity. The increase from $1 \mathrm{gr}$ to $2.5 \mathrm{gr}$ of coagulant decreases this fraction from 0.19 to 0.14

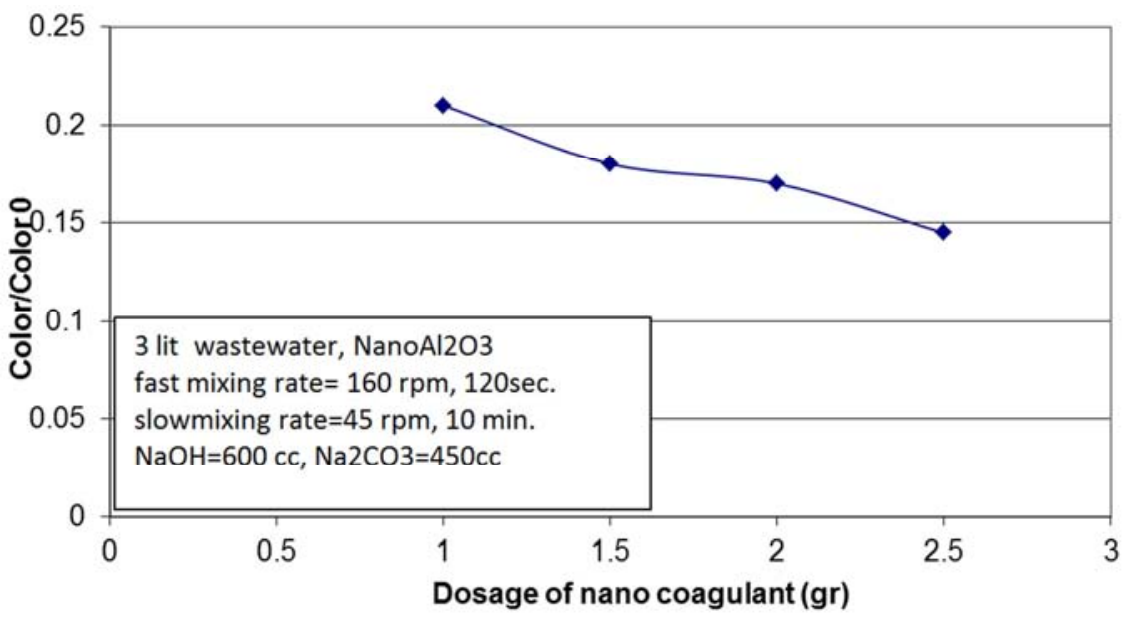

Figure 6. The amount of color/color0 removal versus aluminum oxide nano coagulant.

Figure 6 shows the effect of nano aluminum oxide on the value of color/clolor0. This ratio decreases from 0.21 to 0.14 using 1 gr to 2.56 gr of nano aluminum oxide. Comparing these results with those are obtained for using of nano ferric oxide show the higher performance of nano ferric oxide about $10 \% .0 .5 \%, 0.6 \%$ and $0.4 \%$ in ratio of color/color 0 than aluminum oxide.

\section{Conclusion}

The performance of two nano coagulant in pretreatment of wastewater from refinery is presented in this experimental work. Refinery wastewater includes oil, grease as contaminants. The dosage of nano coagulant changes in values of 1, 1.5, 2 and 2.5 gr. Both nano ferric oxide and aluminum oxide show the positive effect in elimination of dangerous components. The increase in the amount of each nano coagulant increases the effect of them in contaminant removal. Results obtained from ferric oxide usage $(1,1.5,2$ and 2.5 gr) show the higher value about $20 \%, 18 \%, 20 \%$ and $9.5 \%$, respectively. The higher values of nitrate elimination percentage are obtained in usage of ferric oxide about $12 \%$, $17 \%, 12 \%$ and $15 \%$, respectively than those are obtained from aluminum oxide. In elimination of the other contaminants the nano ferric oxide shows the more effective influence in pretreatment process than nano aluminum oxide. The value of zeta potential of nano aluminum oxide is averagely $5 \%$ higher than values obtained from using nano ferric oxide, so the nano ferric oxide shows the better coagulation and flocculation. The average amount of slug value index by using nano ferric oxide is $16 \%$ higher than that is obtained from the addition of nano aluminum oxide. The experimental results show the higher values of zeta potential in about $1 \%, 3 \%, 11 \%$ and $5 \%$ using aluminum oxide than those are obtained using nano ferric oxide show the better coagulation and flocculation in using nano ferric oxide nano coagulant. Also, the results state, the increase from $1 \mathrm{gr}$ to $2.5 \mathrm{gr}$ of coagulant decreases this fraction from 0.19 to 0.14 . In addition, the comparing these results with those are obtained for using of nano ferric oxide show the higher performance of nano ferric oxide about $10 \%$. $0.5 \%$, $0.6 \%$ and $0.4 \%$ in ratio of color/color 0 than aluminum oxide.

\section{References}

[1] Al-Jasser A., 2011. Saudi wastewater reuse standards for agricultural irrigation: Riyadh treatment plants effluent compliance [J]. King Saudi University - Eng Sci, 23: 1-8.

[2] Gao B., Chu Y., Yue Q., 2009. Purification and characterization of $\mathrm{Al} 13$ species in coagulant polyaluminum Chloride [J]. J Environ Sci, 21: 18-22.

[3] Jangkorn S., Kuhakaew S., Theantanoo S., Klinla-or H., Sriwiriyarat T., 2011, Evaluation of reusing alum sludge for the coagulation of industrial wastewater containing mixed anionic surfactants [J]. J Environ Sci, 23: 587-594.

[4] Khiari R., Dridi-Dhaouadi S., Aguir Ch., Farouk Mhenni M., 2010. Experimental evaluation of eco-friendly flocculants prepared from date palm rachis [J]. J Environ Sci, 22: 15391543.

[5] Lee S., Maniquiz M., Kim L., 2010. Characteristics of contaminants in water and sediment of a constructed. wetland treating piggery wastewater effluent $[\mathrm{J}]$. J Environ Sci, 22: 940-945.

[6] Nan J., He W., Song X., Li G., 2009. Impact of dynamic distribution of floc particles on flocculation effect $[\mathrm{J}]$. J Environ Sci, 21: 1059-1065.

[7] Pa B., Roca J., Piáa A. B., 2009. Application of multicriteria decision analysis to jar-test results for chemicals selection in the physical-chemical treatment of textile wastewater $[\mathrm{J}]$. J Hazard Mater, 164: 288-295. 
[8] Wu Q., Hua 1 T., Zhou Q., 2011. Treatment and remediation of a wastewater lagoon using microelectrolysis and modified DAT/IAT methods [J]. J Environ Sci, 23: 388-395.

[9] Setiawan A. A., Zhao Y., Nayar Ch. V., 2009. Economic analysis and environmental considerations of mini-grid hybrid power system with reverse osmosis desalination plant for remote areas [J]. Renew Energ, 34: 374-383.

[10] Wang W., Li H., Wang X., Liu Y., 2010. Spatial variations of aluminum species in drinking water supplies in Xi'an studied applying geographic information system $[\mathrm{J}]$. J Environ Sci, 22: 519-525.

[11] Wang Y., Zhoua W. Z., Gao B. Y., 2009. The effect of total hardness on the coagulation performance of aluminum salts with different Al species [J]. Sep Purif Technol, 66: 457-462.

[12] Yana M., Wang D., Ni J., Qu J. W., 2009. Natural organic matter (NOM) removal in a typical North-China water plant by enhanced coagulation: Targets and techniques [J]. Sep Purif Technol, 68: 320-327. 